\title{
o ser humano e o mistério amoroso de Deus: a contribuição de Karl Rahner para a reflexão hodierna sobre a experiência de Deus
}

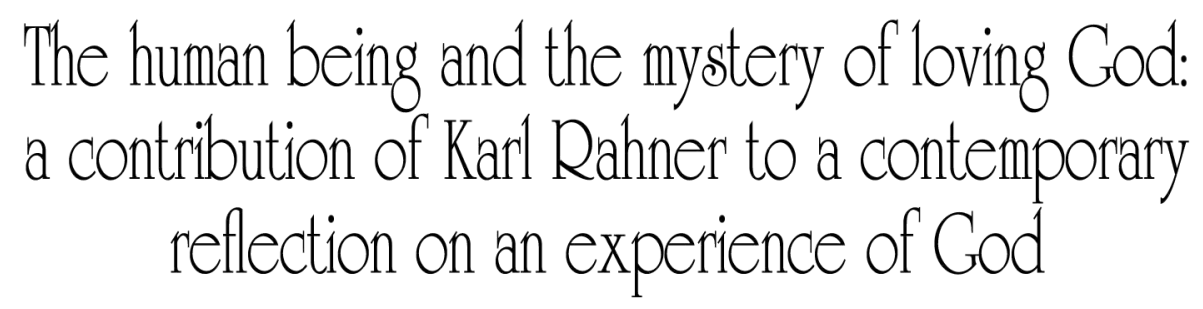

Renato da Silva Machado*

Resumo: Celebramos o ano da Fé no qual somos convidados a aprofundar o conhecimento de Deus redescobrindo a beleza de ser discípulo e missionário do Senhor Jesus. No intuito de colaborar nesta tarefa, nos propomos estudar a questão da experiência de Deus segundo a perspectiva teológica de Karl Rahner, que com sua teologia transcendental nos possibilita perceber o ser humano como ser de abertura ao Mistério de Deus como também percebermos a missão de apresentarmos hoje a experiência de Deus como caminho de realização do ser humano.

Palavras-chave: Fé, Experiência, Transcendental, Realização.

Abstract: We are celebrating the Year of Faith, in which we are invited to deepen our knowledge of God, by rediscovering the beauty of being disciples and missionaries of the Lord Jesus. In order to collaborate

* Presbítero, mestre em Teologia Sistemático-Pastoral pela Pontifícia Universidade Católica do Rio de Janeiro e doutorando na mesma universidade e como também na Pontificia Facoltà Teologica dell'Italia Meridionale. Bolsita da CAPES Proc. n. 1230-81-2. E-mail: remadc@hotmail.com. 
in this task, we intend to study the issue of the experience of God within Karl Rahner transcendental theological perspective, which allows us to see that the human being is open to the Mystery of God as well as that we have the mission to present the experience of God as the way of realization of the human being.

Keywords: Faith, Experience, Transcendental, Realization.

\section{Introdução}

Estamos com toda a Igreja celebrando o ano da Fé. Nele somos chamados a aprofundar o conhecimento amoroso de Deus redescobrindo a beleza de ser discípulo e missionário do Senhor Jesus. Como cristãos somos chamados a voltar-nos ao coração do cristianismo é que a experiência com o Ressuscitado o qual nos confere a graça de conhecer o Pai mediante o seu Espírito, experiência que é a razão do ser cristão. De fato, não se começa a ser cristão a partir de uma simples adesão intelectual mas a partir de um encontro que envolve a pessoa inteira e determina a vida daquele que faz esta experiência. ${ }^{1} \mathrm{O}$ encontro com Jesus Cristo conduz à fé trinitária, uma vez que este é o Filho de Deus e ungido pelo Espírito Santo: crer em Jesus é crer no Deus uno e Trino, mistério central da fé e da vida cristã ${ }^{2}$

Desta forma, no aprofundamento da fé, a pergunta sobre Deus não é uma questão secundária, mas a questão principal. Se a fé cristã é acima de tudo cristológico-trinitária, o estudo da questão de Deus deve ser a preocupação principal da teologia e do cristão. Isto se faz mister sobretudo no contexto plural no qual vivemos onde há diversas formas de se acreditar em Deus e vivenciar esta fé, como também de contestá-lo. Ao sondar os mistérios de Deus, a teologia deve perceber

\footnotetext{
BENTO XVI. Carta encíclica Deus caritas est, n. 1. Disponível em: <http://www.vatican. va/holy_father/benedict_xvi/encyclicals/documents/hf_ben-xvi_enc_20051225_deusva/holy_father/benedict_xvi/encyclicals/docu

Catecismo da Igreja Católica, n. 234. Disponível em: <http://www.vatican.va/archive/ cathechism_po/index_new/p1s2c1_198-421_po.html>. Acesso em: 31/01/2013
}

a urgência de comunicar hoje a experiência do Deus vivo como uma proposta de sentido para o ser humano hoje.

No intuito de colaborar nesta tarefa de refletir sobre a questão de Deus é que se apresenta este trabalho. Trata-se de um estudo sobre a questão de Deus e de como o ser humano realiza a experiência com Deus segundo a perspectiva teológica de Karl Rahner. Este teólogo mostra o ser humano como ser de transcendência, ser que se realiza a si mesmo na medida em que se abre a relação com o Mistério Absoluto, realizada em situações mais simples da vida, em experiências muitas vezes tematizadas ou tidas como "a-religiosas". Entender o ser humano como ser aberto ao Mistério significa perceber a oportunidade de apresentar no contexto atual a proposta cristã sem temor acreditando que a proposta que a Igreja pode oferecer ao mundo é proposta de Salvação.

\section{A questão de Deus hoje}

\subsection{0 paradigma da autonomia do sujeito}

A modernidade iniciou um novo paradigma, marcado, sobretudo, na autonomia e individuação do ser humano. ${ }^{3} 0$ paradigma pré-moderno, pautado nas explicações mitológicas e teológicas entra em crise na medida em que não consegue mais dar uma resposta plausível aos novos problemas que vão se configurando na sociedade: na física, de uma cosmologia dependente dos deuses se passa a uma regida com suas leis próprias; na realidade social, econômica e política as relações deixam de ser fruto de uma vontade divina, legitimada pela religião, para serem entendidas como vontade e liberdade de indivíduos concretos; na psicologia de uma conduta pautada na moral religiosa, na verificação das ações e reações da consciência e inconsciência, se propõe a autonomia do indivíduo. O ser humano percebe-se como centro da criação e sujeito autônomo.

3 Cf. TORRES QUEIRUGA, Andrés. Fim do cristianismo pré-moderno: desafios para um novo horizonte. São Paulo: Paulus, 2003. p. 20-25. 
Essa autonomia, no entanto, desenvolvida sem referenciais, trouxe a sociedade enormes prejuízos. Hoje, percebem-se as consequências de uma autonomia desconexa de uma ética que intensificou a indústria armamentista, a degradação do meio ambiente e as diversas enfermidades físicas, psicológicas (depressão, esquizofrenia, suicídio) e mesmo econômicas (desemprego inflação, desigualdade social) que ameaçam a vida dos ecossistemas, da sociedade e do próprio indivíduo. ${ }^{4}$ Não obstante as consequências de uma autonomia desenfreada, percebe-se que a autonomia do ser humano é uma conquista legítima e um processo irreversível que deve ser trilhado no caminho de uma verdadeira liberdade. ${ }^{5}$

\subsection{Autonomia do sujeito e religião}

O influxo da autonomia do ser humano presente nos diversos segmentos da vida humana, não é diferente em relação à religião, na qual assistimos a desconstrução dos sistemas tradicionais de crença. Hoje se difunde uma mentalidade de na qual o ser humano é autônomo na configuração de sua regra de fé. Além disso, percebe-se a grande mobilidade religiosa em que os indivíduos transitam em sistemas religiosos diversos e até antagônicos. Trata-se de um novo tipo de religiosidade na qual a experiência subjetiva do indivíduo é determinante chamada de "bricolagem religiosa”, 6 ou seja, o processo de apropriação de elementos numa nova configuração religiosa elaborado pelo sujeito.

Se, por um lado, percebe-se o encolhimento da religião seja em relação à proporção de adeptos, seja no poder de influência na política e na vida social, por outro lado verifica-se a proliferação da religiosidade através das chamadas religiões "a la carte”, de uma religiosidade "flutuante”, de crenças "relativas”, de novas elaborações sincréticas... Com isto transparece que o crer, na sociedade moderna, está desassociado do ser religioso: Não é o fato de “crer em Deus”, como se pensou

\footnotetext{
${ }^{4}$ Cf. CAPRA, F. O ponto de mutação. São Paulo: Cultrix, s/d, p. 19-225.

Cf. TORRES QUEIRUGA, Andrés. op. cit., p. 22.

HERVIEU-LEGER, Danièle. O peregrino e o convertido: a religião em movimento. Petrópolis, RJ: Vozes, 2008. p. 41.
}

no passado, que torna o ser humano religioso. ${ }^{7}$ É possível “crer em Deus” de maneira não religiosa, através de uma experiência mística, iluminação interior, contemplação estética ou engajamento ético sem filiação ou adesão a um sistema religioso. A crença só é religiosa quando o crente coloca diante de si a lógica do desenvolvimento que o leva a crer naquilo que crê.

A religiosidade é construída nesta nova época a partir do sujeito que faz a experiência transcendental e por ele. Há uma diferenciação entre a pertença confessional e a aceitação da confissão religiosa da mesma instituição. Muitos se declaram pertencer a determinado seguimento religioso, no entanto, acreditando em crenças diversas e até mesmo opostas à confissão de seu seguimento.

Podemos ter reservas em relação a essa nova religiosidade que se apresenta, mas havemos de concordar que ela traz em relevo algo que é fundamental no cristianismo - a experiência que a pessoa faz em primeira pessoa do Mistério de Deus em Cristo. A experiência pessoal do Mistério de Deus mais do que nunca aparece em relevo convocando a todos a refletir sobre o tornar-se cristão. ${ }^{8}$ Evidencia-se a necessidade de fazer dos cristãos verdadeiros convertidos, místicos, pessoas que fizeram um encontro com Cristo capaz de subverter as suas vidas. Fica mais latente a constatação e/ou convite provocador de Karl Rahner: "0 cristão do futuro, ou será místico ou não será cristão”. ${ }^{9}$ Nesse sentido, vemos por bem refletirmos sobre a questão da possibilidade da vida mística, da relação entre Deus e o ser humano, utilizando-nos para tal intento do referencial teórico de Rahner. ${ }^{10}$

7 Ibid., p. 26-27.

8 Pensamos que não é por acaso que a categoria "encontro" seja uma categoria-chave na compreensão da teologia de Bento XVI.

9 RAHNER, Karl. O cristão do futuro. São Paulo: Cristã Novo Século, 2004. p. 78.

${ }^{10}$ Karl Rahner nasceu em Friburgo na Alemanha em 1904 e morreu em Innsbruc, na Áustria em 1984. Em 1922, aos 18 anos, entrou para a Companhia de Jesus professando os votos e em 1932 foi ordenado sacerdote. Doutor em teologia, contribuiu no Concílio Ecumênico Vaticano II, primeiro como conselheiro do cardeal Franz König, depois como especialista da comissão teológica, onde se destacava pelo zelo a tradição católica e sua especialista da comissão teológica, onde se destacava pelo zelo a tradição católica e sua
preocupação com o novo paradigma que ia se fixando no mundo. Em suas obras de teologia, influenciadas pelos exercícios espirituais, busca refletir sobre o mistério de Deus enquanto mistério de salvação para nós; o "proveito do mistério divino para nós". 


\section{O ser humano como ouvinte da Palavra}

\subsection{0 ser humano como ser transcendental}

Uma das primeiras reflexões de Karl Rahner (que mais tarde seriam publicadas) tinha o título: o ouvinte da Palavra. ${ }^{11}$ Sua obra "Curso fundamental da fé”, na sua primeira seção, base para as seguintes, guarda o mesmo título e reflexão. Trata-se em deter naquele a quem é dirigida a autocomunicação de Deus e percebê-lo como ser que possui a possibilidade de receber esta autocomunicação.

Rahner afirma que o ser humano é em primeiro lugar pessoa e sujeito. Pessoa e sujeito enquanto ser transcendental, dotado de responsabilidade e liberdade, possuidor da referência ao mistério inconpreensível, de historicidade e necessária inserção no mundo e sociabilidade. ${ }^{12}$ Ele experimenta-se como sujeito e pessoa na medida em que consegue se distanciar do todo, tornando-se consciente de que é fruto de algo que lhe é radicalmente estranho; e constitui-se de fato como pessoa e sujeito na relação consciente e livre para com o todo. Sendo que esta relação não é feita somente por uma parte do ser humano - como foi entendido pela teologia escolástica ao tratar da alma imortal, numa compreensão dualista que na verdade é da filosófica grega e não propriamente uma compreensão cristã - mas feita pelo ser humano inteiro enquanto uma unidade. ${ }^{13}$ Nesse sentido, podemos perceber já aqui que espiritualidade na compreensão do autor não se trata de expressão de uma parte do ser humano, mas do ser humano na sua totalidade.

Ao tratar do ser humano enquanto possibilidade de relação, Rahner quer apontar para a subjetividade deste, que o diferencia dos demais seres, da consciência e liberdade com as quais se pode autopossuir e estabelecer relações com a totalidade do ser. Esta experiência subjetiva lhe permite também perceber que não é o ser em

${ }^{11} \mathrm{Na}$ tradução italiana pode ser assim encontrada: RAHNER, Karl. Uditori della parola. Roma: Borla, 2006

${ }^{2}$ RAHNER, Karl. Curso fundamental da fé. São Paulo: Paulus, 1989, 2004. p. 39

${ }^{13}$ Ibid., p. 43-44. sua plenitude "mas justamente enquanto ele se pergunta pelo ser, revela-se como não sendo simplesmente o ser, a questionabilidade implica distância e, portanto, o ente que pergunta não é o ser”.14

O ser humano percebe-se como finito e que está diante de um horizonte mais amplo e sente-se tocado por este horizonte maior. Esta experiência é chamada por Rahner de transcendental:

Essa experiência é chamada transcendental porque faz parte das estruturas necessárias e insuprimíveis do próprio sujeito que conhece [...]. A experiência transcendental é a experiência da transcendência, experiência na qual a estrutura do sujeito e, consequentemente, também a estrutura última de todo objeto concebível de conhecimento está presente conjuntamente e na identidade. ${ }^{15}$

A partir dessa experiência o ser humano percebe-se como ser transcendente, espírito, ser de horizonte infinito. Desse modo, podemos perceber a experiência como aquilo que permite o ser humano perceber-se a si mesmo e, portanto, realizando a si mesmo enquanto ser de abertura, como "ouvinte da Palavra”. Destarte, há de se ter claro que esse mesmo ser humano pode esquivar-se dessa experiência seja por ingenuidade, não demandando tempo para tal, seja por se perguntar por esse transcendente, mas não permitir uma possibilidade de resposta para o mesmo; ou seja, por querer de fato ignorar a experiência transcendental. E neste sentido, a negação da experiência transcendental, ao contrário do que muitas vezes se pensa, não é a prática de uma autêntica liberdade ${ }^{16}$ e responsabilidade, mas trata-se de "uma possibilidade da liberdade que ao mesmo tempo sempre representa algo de falho, descarrilado, malogrado, algo que, por assim dizer, é autodestrutivo e autocontraditório". ${ }^{17}$ Significa assumir uma postura de vida que de modo algum edifica o ser humano enquanto pessoa, mas que ao contrário, nega a esta a possibilidade de autorrealização.

${ }^{14}$ OLIVEIRA, MANFREDO. Filosofia transcendental e religião, p. 124. In: FERNANDES, Rafael Morello. O ser humano: local do encontro com Deus; abertura transcendental e autocomunicação divina em Rahner. Dissertação de Mestrado. PUC-RJ, 2005, p. 30.

${ }^{15}$ RAHNER, Karl. Curso fundamental da fé, p. 33.

${ }^{16}$ Liberdade segundo o autor não se trata da possibilidade de se fazer isso ou aquilo, mas da realização do ser humano a si mesmo enquanto ser transcendental e capaz de decidir-se sobre si mesmo. Cf. RAHNER, Karl. Curso fundamental da fé, p. 54.

${ }^{17}$ Ibid., p. 128. 


\subsection{0 ser humano e a tematização de Deus}

Se a experiência transcendental é a possibilidade do ser humano realizar-se enquanto ser de transcendência, há de se perceber que este Outro para o qual o ser humano dirige-se trata-se do Mistério último, que costumeiramente chamamos "Deus". A experiência do Outro na experiência transcendental é de fato, única e inexpremível e havemos perceber sempre a diferença entre aquilo que a palavra quer expressar e a experiência em si. No entanto necessitamos de uma palavra que venha expressar esse "Outro" com quem nos relacionamos. Para isso utilizamos a palavra "Deus". Trata-se de uma palavra utilizada em nosso ambiente cultural e que tende a se perpetuar até mesmo através daqueles que negam a experiência com ele, como sua existência. Também estes ajudam a perpetuar a palavra Deus. ${ }^{18}$

Essa diferenciação entre realidade em si e realidade enquanto conceito permite-nos perceber que pessoas de diferentes credos, como também as que não participam de um credo específico, ou ainda mesmo, aquelas que dizem não acreditar em Deus, possam ter uma experiência com este denominado por nós "Deus" chamando-o de outra forma ou mesmo não tematizando tal experiência. A palavra Deus, no entanto, parece que consegue refletir aquilo que se propõe:

“o Inefável”, o “Sem nome”, o que não aparece no mundo designado como um componente dele; o "Silencioso" que está sempre aí e sempre pode passar despercebido e não ser ouvido [...] aquele que não pode designar-se por uma palavra [...] e em consequência, só é inteligível dentro de um campo de palavras ou jogo de linguagem. ${ }^{19}$

\subsection{A experiência atemática de Deus}

Mais importante do que Deus enquanto conceito abstrato é a relação, a experiência que se tem dele na qual somente o discurso teológico e metafísico se tornam compreensíveis. Essa experiência é realizada de forma categorial, sempre mediada por atos concretos nossos no mundo. Trata-se de uma experiência na história, e não fora da revelação. ou não.

O encontro com Deus neste sentido é sempre mediado pela subjetividade que "já é desde o seu ponto de partida a transcendência que escuta, que não controla, que é conquistada pelo mistério, que é aberta ao mistério". ${ }^{20}$ Essa sedução, esta conquista do ser humano pelo mistério possibilita a tentativa de expressão desta experiência.

Ora, se a experiência de Deus é subjetiva, enquanto é o ser humano concreto que a experimenta, pode vir a ser também objetivada, ser expressa em categorias compreensíveis. Somente nesse sentido, Rahner nos ensina que podemos falar em "provas" da existência de Deus. Estas provas não são como algo exterior que venha a se impor e substituir a experiência subjetiva, mas visam somente apontar que o ser humano enquanto transcendente em qualquer momento de sua existência se depara com a questão de Deus decidindo por refleti-la

O Deus que se relaciona conosco é, como afirma a tradição cristã, um ser pessoal. Pessoal não enquanto limitado por algo de fora, outra realidade, mas enquanto que, limitando todas as coisas e estabelecendo-as nas diferenças, pode relacionar-se com elas e de fato se relaciona na subjetividade individual, na oração e na história pessoal. ${ }^{21}$ E neste sentido em que é deslumbrada a criação, como possibilidade dada por Deus do ser humano se relacionar com ele que se autocomunica no amor.

\section{A autocomunicação de Deus ao ser humano}

\subsection{0 primado da experiência da autocomunicação de Deus}

Ao tratarmos da autocomunicação de Deus convém ressaltarmos inicialmente que se trata da livre e amorosa vontade e iniciativa de 
Deus. Esta autocomunicação livre e amorosa, segundo Rahner, não vem a nós como algo de fora, como se fosse uma revelação na qual Deus falasse algo de si. Trata-se antes do mistério amoroso de Deus que se faz presente ao ser humano a partir da própria estrutura transcendental deste, não como algo, como uma característica de Deus perceptível pelo ser humano, mas como Deus mesmo vindo ao seu encontro.

A autocomunicação de Deus significa, portanto, que a realidade comunicada é realmente Deus em seu próprio ser, e desta forma é comunicação que tem em mira conhecer e possuir a Deus na visão imediata e no amor. $^{22}$

É Deus que vem ao ser humano enquanto este tem em si mesmo a possibilidade desta autocomunicação divina, enquanto é ser de transcendência. Nesse encontro amoroso com Deus, o ser humano faz experiência daquilo que Deus é em si mesmo, pois se encontra com o próprio Deus, pois aquele que se autocomunica é ao mesmo tempo doador e dom. Aquele que dá, não dá algo, mas dá-se si mesmo ao ser humano. No entanto, devemos perceber que esta autocomunicação divina não se permite ser apreendida pelo ser humano como uma realidade categorial. Deus é aquele que "não permite que dele se disponha, mas que é a instância infinita e muda que dispõe de nós no momento e todas as vezes que começamos a dispor de alguma coisa”. ${ }^{23}$

Esse Deus que se autocomunica e que continua sendo mistério insondável não se autocomunica por solidão ou qualquer forma de carência, mas ao contrário, se autocomunica por ser "absolutamente feliz e realizado". ${ }^{24}$ Assim o faz não porque necessita, mas porque se decide na liberdade e no amor autocomunicar-se, transbordar-se em amor. A autocomunicação de Deus é tão importante para a experiência cristã que a própria criação do ser humano é vista nesta perspectiva. Ao criar o ser humano, Deus quer revelar-se a ele na intimidade de seu ser, e este, ao ser criado torna-se então a possibilidade

${ }^{22}$ Ibid. p. 147.

${ }^{23}$ RAHNER, Karl. O dogma repensado. São Paulo: Paulinas, 1970. p. 181

${ }^{24}$ Id. Curso fundamental da fé, p. 152-153. de Deus de se autocomunicar no amor, pois é criado como ser de autotranscendência. ${ }^{25}$

Enquanto ser de autotranscendência, o ser humano pode se relacionar com o mistério. Esta possibilidade, que diz respeito a todos e a cada um dos homens e mulheres é designado por Rahner como existencial sobrenatural. Trata-se da abertura do ser humano ao mistério que constitui o seu próprio ser e que o permite realizar-se enquanto pessoa. Nesse sentido, o mistério insondável que é Deus não é algo estranho ao ser humano, mas a "experiência de que esse mistério santo é proximidade acolhedora, a intimidade que perdoa abrigo na fuga à estranheza vazia e ameaçadora de sua própria vida”. ${ }^{26}$ E a experiência por sua vez, com este distante-próximo por não ser algo de extraordinário, estranho a existência humana, ocorre nas coisas mais simples da vida, nas experiências que podem ser atemáticas e irreligiosas. ${ }^{27}$ Aqui temos uma grande contribuição do autor em relação a teologia da espiritualidade: viver e fomentar a espiritualidade não significa apenas a experiência emotiva de alguns momentos convencionalmente tidos como religiosos, mas trata-se do acolhimento do mistério realizado no cotidiano da vida, experimentado sem ritualismos ou formalidades. Não se trata de forma alguma negar a experiência de Deus no rito, mas antes situá-lo na existência do indivíduo, em plena relação com o cotidiano de vida.

\subsection{A autocomunicação da Trindade imanente na Trindade econômica}

Rahner nos apresenta que a autocomunicação de Deus a nós trata-se do próprio Deus que vem ao nosso encontro e ensina ainda que esta autocomunicação divina na história da salvação não pode ser diferente do Deus em sua imanência: “A Trindade 'economica’ é

${ }^{25}$ Cf. Id. Reflexões fundamentais sobre a antropologia e a protologia no conjunto da teologia. In: FEINER, Johannes; LÖHRER, Magnus. Mysterium Salutis II/2. Petrópolis, RJ: Vozes, 1972. p. 6-19.

${ }^{26}$ Id. Curso fundamental da fé, p. 163.

${ }^{27}$ Ibid., 164 . Exemplos dessa experiência de Deus realizada no cotidiano da existência podem ser vistos em RAHNER, Karl. Experiencia Del Espíritu. Madrid: Narcea, 1977. p 47-53. 
a Trindade 'imanente' e vice-versa”. ${ }^{28} \mathrm{O}$ axioma trinitário de Rahner mostrará que a reflexão sobre Deus não deve partir de uma reflexão metafísica (do pensar a Deus como causa primeira de todas as coisas, princípio não causal...), antes deve partir do autocomunicação histórica de Deus. Que se autocomunicou em Jesus Cristo como lemos no prólogo de João:

E o Verbo se fez carne e habitou entre nós e nós vimos a sua glória, glória que ele tem junto ao Pai como Filho único, cheio de graça e de verdade. Pois a Lei foi dada por meio de Moisés; a graça e a verdade vieram de Jesus Cristo. Ninguém amais viu a Deus: o Filho único, que está voltado para o seio do Pai, este o deu a conhecer (Jo 1,14.16-18)

Esse texto nos mostra que a revelação de Deus é realizada em Jesus Cristo. Ele é quem nos revela a Trindade. E a revelou não para simplesmente tomarmos conhecimento intelectivo desta realidade, mas sim para que esta realidade seja acolhida por nós enquanto proximidade e salvação. 0 Deus de nossa fé não pode ser pensado como "mistério lógico", mas sim como "mistério de salvação". ${ }^{29}$ O Deus revelado em Jesus autocomunica-se não numa retórica filosófica, mas na história salvífica. Há de se proceder então sempre partindo do nível da economia (Deus agindo em nosso favor e por nós) em direção ao nível da imanência (Deus em sua vida eterna e perfeita comunhão entre as divinas pessoas).

A autocomunicação de Deus, Mistério Santo que vem ao nosso encontro em Verdade e Amor o faz através da missão do Filho e do Espírito Santo. É através da missão do Filho, o Verbo que se encarna, e da missão do Espírito Santo que conhecemos o Pai. E assim sendo podemos então fazer a experiência do Deus Trindade. Deus vem a nós enquanto salvação divinizante, e o chamamos Espírito Santo. Vem a

${ }^{28}$ RAHNER, Karl. O Deus Trino, fundamento transcendente da história da salvação. In: FEINER, Johannes; LÖHRER, Magnus. Mysterium Salutis II/1. Petrópolis, RJ: Vozes, 1972. p. 293.

${ }^{29}$ BINGEMER, Maria Clara Lucchetti. Um Deus para ser amado: algumas reflexões sobre a doutrina trinitária em Karl Rahner. In: OLIVEIRA, Pedro Rubens F. de; PAUL, Cláudio (org.). Karl Rahner em perspectiva. São Paulo: Edições Loyola, 2004. p. 66. nós enquanto participa de nossa história concreta e o chamamos de Jesus Cristo. Enquanto vem a nós como Espírito e Filho, e se mantém inefável, nós o chamamos de Pai. Enquanto vem a nós como Espírito, Filho e Pai de maneira diversa e ao mesmo tempo uma nós podemos o chamar de Deus Uno e Trino, mistério da nossa salvação. ${ }^{30}$ É a partir da história da salvação que sabemos que Jesus é o Filho de Deus e que o Espírito Santo é dom do Filho e do Pai. E, por sua vez, o modo como as pessoas divinas se relacionam na história há de ser também o modo como elas se relacionam entre si..$^{31}$ Assumindo a perspectiva da economia, Rahner chega ao ponto de afirmar que a união hipostática do Verbo já manifesta seu próprio ser intradivino e é exclusivo da Segunda Pessoa, assim como também pensa que a presença do Espírito Santo como dom também é exclusivo da Terceira Pessoa. ${ }^{32}$

O axioma rahneriano, no entanto, pode deixar maus entendidos, entre os quais o de reduzir o Mistério de Deus à revelação histórica. Nesse sentido que Bruno Forte, entre outros, dirige uma dura crítica ao "vice-versa" do axioma afirmando que este não pode ser aceito na teologia trinitária por se tratar de uma dissolução do divino no terreno, de um aprisionar a Trindade na história e com isto suprimir a transcendência divina na revelação. ${ }^{33} \mathrm{~A}$ crítica de Forte procura salvaguardar a transcendência divina de modo que a Trindade imanente não seja reduzida à Trindade econômica, pois, segundo ele, por mais que o Mistério Trinitário se apresente e é Mistério de Salvação, não pode ser reduzido a uma contingência histórica, mas antes deve ser percebido como Mistério insondável, fonte, no amor e na liberdade, de todo o mundo criado. Tal crítica mostra-se pertinente porque traz em ressalto que a economia não diz tudo sobre o Mistério, que continua lá no alto, inatingível ao ser humano, no entanto compreendemos que o vice-versa do axioma não traz prejuízo a fé se visto no conjunto da reflexão de Rahner na qual está preocupado em enfatizar a comunica-

${ }^{30}$ Cf. RAHNER, Karl. Curso Fundamental da fé, p. 168-169.

${ }^{31}$ RAHNER, Karl. O Deus Trino, fundamento transcendente da história da salvação. In FEINER, Johannes; LÖHRER, Magnus. Mysterium Salutis II/1, p. 343-344.

32 MIRANDA, Mario de França. O mistério de Deus em nossa vida. São Paulo: Loyola, 1975 p. $67-108$.

${ }^{33}$ Cf. FORTE, B. Teologia da história: ensaio sobre a revelação, o início e a consumação São Paulo: Paulus, 1995. p. 55 
ção de Deus entre os homens, mas do que refletir sobre o mistério da Trindade imanente, não submetendo em momento algum a imanência à economia, mas ao contrário afirmando que a auto comunicação se dá de forma livre e gratuita. ${ }^{34} \mathrm{O}$ mesmo Rahner indicou que a autocomunicação divina não se permite ser apreendida pelo ser humano como uma realidade categorial: "Deus é aquele que não permite que dele se disponha, mas que é a instância infinita e muda, que dispõe de nós no momento e todas as vezes que começamos a dispor de alguma coisa". ${ }^{35}$

Tanto a tese quanto a antítese leva-nos a concluir que a Trindade existe para além da história, independentemente de qualquer revelação histórico, mas que ao mesmo tempo esta Trindade fez da história, história de salvação, "lugar" de autocomunicação e expansão da graça.

\subsection{A autocomunicação como salvação em Jesus Cristo e a atuação da graça em nós como atualização desta salvação}

A autocomunicação de Deus em Jesus Cristo tem sua razão de ser no projeto salvífico de Deus em andamento desde a criação do ser humano. Criação e Encarnação não são nesse sentido realidades justapostas, mas em acordo uma com a outra. Pela Criação se faz a possibilidade da Encarnação do Verbo que é a autocomunicação de Deus e por sua vez a salvação realizada na encarnação do Verbo, é concretude do projeto salvífico iniciado na criação. ${ }^{36}$ Ao criar, Deus faz surgir uma realidade distinta de si mesmo que é o pressuposto para a autocomunicação divina. É uma etapa prévia para a encarnação do Verbo que uma vez encarnado assume esta realidade.

Ao tratar a criação como uma etapa da história salvífica, Rahner faz um diálogo com o pensamento evolucionista, apresentando a meta do mundo realizada na Revelação; e que o ponto alto da Revelação coincide com o ponto alto da abertura transcendental, resultando

${ }^{34}$ Cf. LADARIA, L. A Trindade: mistério de comunhão. São Paulo: Loyola, 2009. p. 11-64. ${ }^{35}$ RAHNER, Karl. O dogma repensado, p. 181

${ }^{36}$ Id. Reflexões fundamentais sobre a antropologia e protologia no conjunto da teologia.

In: FEINER, Johannes; LÖHRER, Magnus. Mysterium Salutis II/2, pp. 6-19. naquilo que chamamos de união hipostática. ${ }^{37}$ Para ele a encarnação do Verbo é uma possibilidade da abertura transcendental do ser humano e a possibilidade da abertura transcendental do ser humano e a possibilidade mais excelsa desta. ${ }^{38}$ Neste sentido a encarnação do Verbo, Jesus Cristo, não expressa somente a realidade de Deus em direção ao ser humano, mas a acolhida do ser humano à este Deus que vem comunicar a salvação. Enquanto esta autocomunicação de Deus se deu em Jesus somente nele, pois se transforma naquele que assumiu, nós chamamos de união hipostática, mas quando se trata da autocomunicação divina que vem a todo e qualquer ser humano, nós chamamos de graça. ${ }^{39}$ A graça de Deus, portanto, trata-se da vinda de Deus a nós enquanto quer comunicar seu amor, que por sua vez, não é algo justaposto a natureza humana, como que fosse distinta desta, mas intrínseca a esta uma vez que o ser humano que é ser transcendental.

\section{Considerações finais}

O estudo sobre a experiência de Deus em Rahner nos dá pistas para elaborarmos um discurso teológico que seja mais adequado para o tempo presente. Dentre estas aqui destacamos duas.

A primeira é a retomada da questão de Deus como tema fundamental da teologia. Nestas últimas décadas discorreu-se sobre temas importantes como a Igreja, os sacramentos, os pobres, no entanto, o presente momento requer uma volta ao centro do cristianismo, a raiz da existência cristã. Mais do que nunca a tematização de Deus deve ser o centro da teologia, sobretudo tendo presente o pluralismo das diversas formas de crenças que pode prejudicar a apresentação e a fé no Deus Trino revelado em Jesus Cristo; e ainda tendo também presente a indiferença para com a questão de Deus, de modo que a teologia possa provocar no coração humano, os questionamentos sobre o sentido da vida humana.

${ }^{37}$ FERNANDES, Rafael Morello. O ser humano, local do encontro com Deus, 2005. p. 48-51. ${ }^{38}$ RAHNER, Karl. Curso fundamental da fé, p. 238-244.

${ }^{39}$ RAHNER, Karl. Foundations of Christian Faith, p. 201. In: FERNANDES, Rafael Molello, op. cit., p. 54 
A segunda questão que ressaltamos é a questão da linguagem teológica. Muitas vezes a teologia é elaborada sem a dimensão existencial que lhe é própria. Separada da história cotidiana dos homens e mulheres se tornou um jogo de palavras técnicas compreensíveis somente para um grupo minoritário na Igreja, incapaz de fomentar a fé. A teologia necessita recuperar a sua dimensão existencial, narrar o Deus que assumiu a história humana autocomunicando-se nela afim de que o ser humano possa encontrar o sentido de sua história na história do Deus feito homem.

Por fim, a questão de Deus e o modo de como se pensar e exprimir esta fé no contexto atual deve mobilizar todos os cristãos de modo que as comunidades paroquiais e os institutos teológicos possam ser grandes centros de espiritualidade e aprofundamento da fé.

\section{Bibliografia}

BINGEMER, Maria Clara Lucchetti. Um Deus para ser amado: algumas reflexões sobre a doutrina trinitária em Karl Rahner. In: OLIVEIRA, Pedro Rubens F. de; PAUL, Cláudio (org.). Karl Rahner em perspectiva. São Paulo: Edições Loyola, 2004.

CAPRA, F. O ponto de mutação. São Paulo: Cultriz, s/d.

COMTE-SPONVILLE, André. O espírito do ateísmo: introdução a uma espiritualidade sem Deus. São Paulo: WMF Martins Fontes, 2007.

DOCUMENTOS DO CONCÍLIO ECUMÊNICO VATICANO II. São Paulo: Paulus, 2004.

FERNANDES, Rafael Morello. O ser humano: local do encontro com Deus; abertura transcendental e autocomunicação divina em Rahner. Dissertação de Mestrado. PUC-RJ, 2005.

FORTE, B. Teologia da história: ensaio sobre a revelação, o início e a consumação. São Paulo: Paulus, 1995.

HERVIEU-LEGER, Danièle. O peregrino e o convertido: a religião em movimento. Petrópolis, RJ: Vozes, 2008.

LADARIA, Luis. A Trindade: mistério de comunhão. São Paulo: Loyola, 2009. O Deus vivo e verdadeiro: o mistério da Trindade. São Paulo: Loyola, 2005.

LACOSTE, Jean-Yves. Dicionário crítico de Teologia. São Paulo: Paulinas/ Loyola, 2004.
MIRANDA, Mario de França. O mistério de Deus em nossa vida. São Paulo Loyola, 1975.

RAHNER, Karl. A exigência de uma "fórmula breve" da fé cristã. Concilium. Revista Internacional de Teologia. São Paulo: Herder, mar. 1967.

. Curso fundamental da fé. São Paulo: Paulus, 1989, 2004.

. Experiencia del Espíritu. Madrid: Narcea, 1977.

. O dogma repensado. São Paulo: Paulinas, 1970.

. O Deus Trino, fundamento transcendente da história da salvação. In: FEINER, Johannes; LÖHRER, Magnus. Mysterium Salutis II/1. Petrópolis, RJ: Vozes, 1972.

. Reflexões fundamentais sobre a antropologia e a protologia no conjunto da teologia. In: FEINER, Johannes; LÖHRER, Magnus. Mysterium Salutis II/2. Petrópolis, RJ: Vozes, 1974

. O cristão do futuro. São Paulo: Cristã Novo Século, 2004.

TORRES QUEIRUGA, Andrés. Fim do cristianismo pré-moderno: desafios para um novo horizonte. São Paulo: Paulus, 2003.

<http://www.vatican.va/holy_father/benedict_xvi/encyclicals/documents/ hf_ben-xvi_enc_20051225_deus-caritas-est_po.html>.

$<$ http://www.vatican.va/archive/cathechism_po/index_new/ p1s2c1_198-421_po.html>. 